\title{
Underrepresentation of Women in Editorial Boards of Scientific and EMS Journals
}

Alessandra Celletti (Università di Roma Tor Vergata, Italy) and Stanislawa Kanas (Rzeszów University, Poland)

One of the fundamental principles of the European Union is the equality between women and men (EU, Article 23 of the "Charter of fundamental rights of the European Union"). As mentioned in [1], "Equal participation of women and men in decision-making is a matter of fairness and is needed to strengthen democracy. It is also likely to benefit the EU's economic growth and competitiveness". The EU Gender Equality Strategy 2020-2025 presents new policy objectives and actions with the aim of reaching a 50-50 gender balance. This is an effort to contribute to the goal set by the EU of offering women and men equal opportunities to thrive by enabling equal participation in all aspects of society.

This note was written as a reaction to the fact that women are still underrepresented on editorial boards of EMS journals relative to their representation among researchers.

\section{Gender gap in STEM subjects}

There is clear evidence of a large imbalance in the participation of women in STEM fields compared to men, in particular at more advanced career levels. This imbalance is more acute in fields that are critical for national economies. In particular, according to data collected by the UNESCO Institute for Statistics (UIS), women represent less than $30 \%$ of the Research \& Development workforce worldwide [2].

These data illustrate that women are globally underrepresented in STEM fields, both in the overall number of graduates (especially at the $\mathrm{PhD}$ level), and in research professions. The "UNESCO Science Report Towards 2030" indicates that gender gaps are more apparent in disciplines such as mathematics, engineering and computer science.

Figure 1 illustrates the gap between women and men, where the underrepresentation of women in STEM subjects translates into the loss of a critical mass of talent.

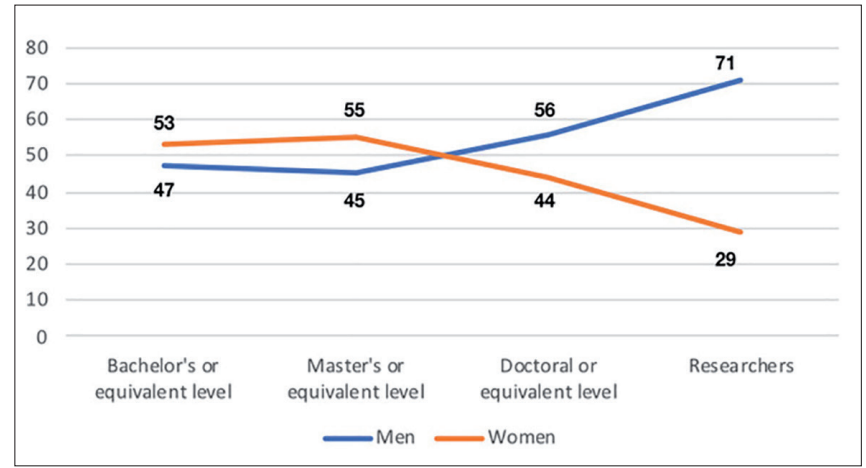

Fig. 1. Proportion of women and men: those that are graduates in tertiary education by programme level and those employed as researchers, 2014. Source: UNESCO Institute for Statistics (UIS) [2].

The UIS findings echo the National Benchmarking Survey 2017 commissioned by the London Mathematical Society [3] for more advanced career stages. Figure 2 exhibits a significant drop in UK female mathematicians from first graduate degree to academic staff. The data presented here is a snapshot of the year 2017, where the total number of lecturers, senior lecturers, researchers (i.e. staff on a research-only contract) and professors (including readers/associate professors as well as full professors) was 3910, of which 805 were women. This 
gives $20.6 \%$ of women academics in the mathematical sciences in the UK in 2017.

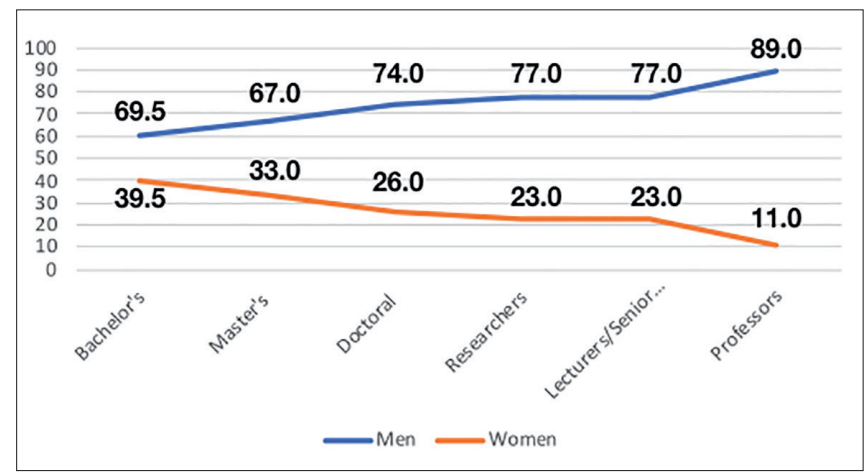

Fig. 2. Percentages of women and men in tertiary mathematics education in the UK in 2017, according to the Benchmarking Survey commissioned by the London Mathematical Society. Source: [3].

This proportion has not increased since the 2005 survey published in [4], which finds that in $2005,20 \%$ of the mathematical sciences tenured faculty positions were held by women in Europe (Denmark, Finland, Iceland, Norway, Sweden, Austria, Belgium, France, Germany, Ireland, The Netherlands, Switzerland, The United Kingdom, Czech Republic, Estonia, Italy, Portugal and Spain).

\section{Gender gap in scientific publication authorship}

Recently, several articles have illustrated the persistence of a gender gap in science, and have sustained and informed the continuing discussions of possible reasons for this discrepancy.

For instance, it has become evident that gender stereotypes do affect the performance of women in mathematics - see [5], since it leads to psychological pressures and (cf. [6]), from a cognitive viewpoint, it reduces individuals' working memory capacity.

The Gender Gap in Science book [7] is a report of the 2017-2019 Gender Gap in Science project [8] which contains the results of a gender analysis of authorship based on several million publications. Figure 3 is a plot taken from [7] that captures a data analysis from zbMATH. Although the plot shows a steady increase in the proportion of women authors, at this rate we will have to wait until 2070 before reaching a balance.

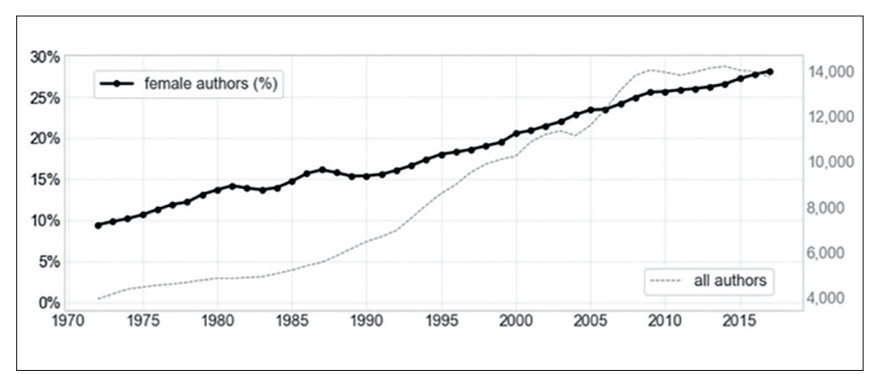

Fig. 3. Number of active (publishing) mathematicians since 1970 and percentage of them that are women. Source: [7].

The findings of the Gender Gap in Science book [7] are in line with the conclusions reached by the authors of [9], who analysed the representation of female authorship in
293,557 research articles from 54 journals covering the categories Life Science, Multidisciplinary, Earth \& Environmental and Chemistry between 2008 and 2016. Their study indicates (a) that $29.8 \%$ of all authorships and $33.1 \%$ of the first, $31.8 \%$ of the co-authors, and $18.1 \%$ of the last authorships were held by women and (b) that in prestigious and highly competitive articles, women are underrepresented with respect to men.

As an illustration, we present the situation for the Journal of the European Mathematical Society in Figure 4.

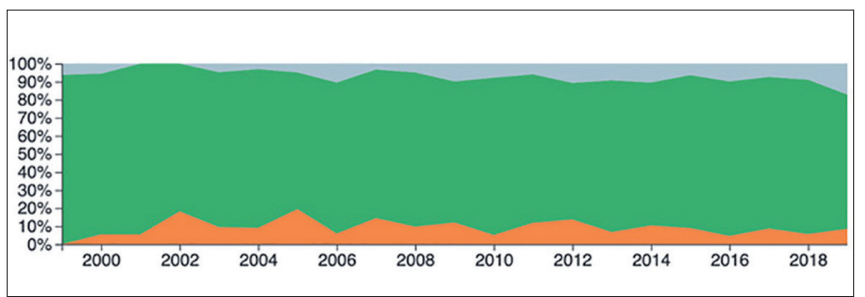

Fig. 4. Proportion of authorships in the Journal of the European Mathematical Society per gender and publication year. Female authors in orange, male authors in green, unidentified gender in grey. Graph obtained using the interactive tools of the Gender Gap in Science project [10].

A study in [11] presents data relating to the publication records of 168 life scientists in the field of ecology and evolutionary biology and supporting the fact that the median number of citations per paper gives no difference between women and men. This, according to the authors of [11], "argues against a quality versus quantity hypothesis". On the other hand, the data provide evidence that there are relatively few women that publish poorly cited articles.

Comparison of h-indices with the number of citations per publication gives the average number of citation of publications of researchers.

From these data, it emerges that female researchers produce higher quality output, whereas males tend to be below the expected productivity with respect to this metric. The conclusion of the authors of [11] is that "for a given level of productivity, females produce better quality work than males". They also conclude that females lead higher quality research compared to their male counterparts with high h-index (years 1996-2005).

\section{Gender gap on editorial boards of scientific journals}

The gender gap in science is also illustrated by the composition of editorial boards of scientific journals. Despite some progress in recent years, the underrepresentation of women on editorial boards remains an important challenge for the scientific community. This underrepresentation pinpoints the numerous obstacles that women still face on their way to reaching higher positions, and limits the global potential of our research community. There is evidence that having a high percentage of male editors leads to a higher percentage of male referees - see [12]. Of course, the refereeing activity is necessary for any scientist, especially for the young ones, since this also makes 
them feel respected in their field. The more prestigious the journal is, the more rewarding the refereeing experience is. According to some editorial comments in Nature (see [13, 14]), this journal has been aware of the gender gap and has been continuously working on improving the situation by applying different types of measures - see also [15]. One of the most notable consequences was the announcement of the first female editor in chief of Nature in 2018.

The gender representation on the editorial boards of 435 journals in the mathematical sciences, listed in the Thomson-Reuters Journal Citation Reports, has been studied in [16]. These journals, of which $35.6 \%$ are in pure mathematics, $43.9 \%$ are in applied mathematics and $20.5 \%$ accept articles from both fields, belong to 123 publishers. The number of editors in the studied group is $27.7 \%$ for pure journals, $51.9 \%$ for applied journals, and $20.4 \%$ for journals publishing both disciplines. For $91.1 \%$ of the data, the authors of [16] found an overall number of 86 countries associated with the editorship. The largest number of editors are the researchers from the US (33.6\%), The United Kingdom (7.4\%), France (6.7\%), Germany (6.6\%), Italy (4.5\%), Canada (4.0\%), Japan (3.8\%), China (3.8\%), Russia (2.4\%), and Australia (2.0\%).

The authors of [16] show that $8.9 \%$ of the 13067 editorships are held by women, $90.3 \%$ by men, and $0.8 \%$ are undetermined (see Figure 5a). This is to be compared and contrasted with the $20.6 \%$ of mathematical sciences tenured faculty positions held by women in 2017 in the UK [3], the $15 \%$ of mathematical sciences tenured faculty positions held by women in 2013 in the United States of America (see $[17,18]$ ) and the $20 \%$ of mathematical sciences tenured faculty positions held by women in 2005 in Europe [4].
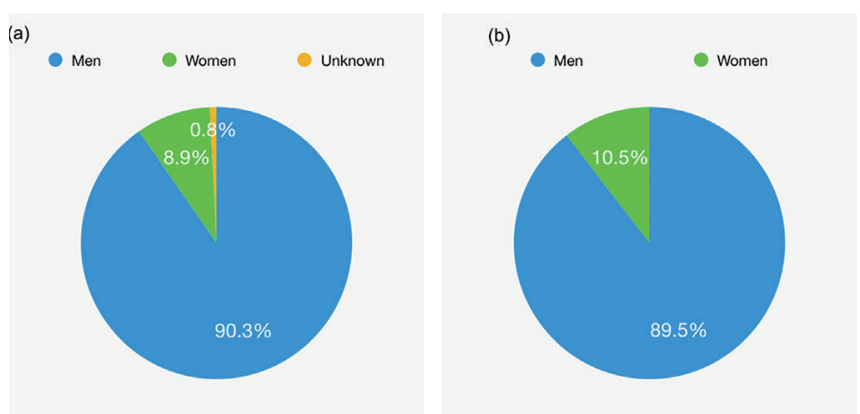

Fig. 5. (a) Gender representation on the editorial boards of 435 journals in the mathematical sciences, listed in the Thomson-Reuters Journal Citation Reports (2013). Adapted from source: https://doi. org/10.1371/journal.pone.0161357;

(b) Gender representation on the editorial boards of the 21 journals from the EMS Publishing House (2020).

As regards gender representation, numbers are not encouraging: the median journal editorial board only includes $7.6 \%$ of women, 62 journals have less than onehalf percent women, while 51 journals (namely $11.7 \%$ of the total investigated journals) have no women at all.

The Women in Mathematics (WiM) committee of the EMS has independently found that the editorial boards of the 21 journals handled by the EMS Publishing House follow the trend of having a very low female representation (Figure $5 \mathrm{~b}$ ). The situation has changed from $8.9 \%$
(42/473) in 2018 to $10.5 \%$ (51/484) in 2020 (where the fractions refer to the number of women editors over the total number of editors). This means that in order to achieve the most conservative percentage of female editors so that it matches the proportion of female researchers in the mathematical sciences (estimated at $20 \%$ ), the EMS Publishing House would have to invite an extra 58 women on board if the number of male editors were to be kept constant at 433 .

If instead we wished to attain a threshold of $30 \%$ women editors, the EMS publishing house would have to invite an extra 135 female editors.

The discrepancy between the percentage of active women mathematicians and that of women acting as editors of scientific journals is totally unacceptable. This is by now a well-documented state of affairs which should be remedied as soon as possible. While we should continue to analyse and resolve the reasons behind this imbalance, we strongly believe the data make such poor reading that the publishers must make it their topmost priority to change the situation with regard to gender balance on editorial boards, thereby demonstrating their commitment to resolving this bias. The WiM committee has the experience to be a helpful resource for the publishers in such an important task.

We are optimistic, however, that the publishers are capable of developing more inclusive strategies of their own in the future.

This note grew out of discussions between all members of the Women in Mathematics committee of the EMS: Alessandra Celletti (Chair), Lisbeth Fajstrup, Stanislawa Kanas, Pablo Mira, Beatrice Pelloni (Past Chair), Elena Resmerita, Marie-Françoise Roy, Elisabetta Strickland, Anne Taormina and Katrin Wendland.

\section{References}

[1] https://ec.europa.eu/info/policies/justice-and-fundamental-rights/ gender-equality/equality-between-women-and-men-decision-making_en

[2] http://uis.unesco.org/en/topic/women-science

[3] National Benchmarking Study 2017, commissioned by the London Mathematical Society; https://www.lms.ac.uk/sites/lms.ac.uk/files/ files/Benchmarking $\ \% 20$ Report $\ \% 20$ FINAL.pdf

[4] Catherine Hobbs and Esmyr Koomen: "Statistics on Women in Mathematics", January 13, 2006; https://womenandmath.files.wordpress.com/2007/09/statisticswomen.pdf

[5] Steven J. Spencer, Claude M. Steele, Diane M. Quinn: "Stereotype threat and women's math performance", J. Exp. Soc. Psychol. 3 (1999), 4-28.

[6] Toni Schmader, Michael Johns: "Converging evidence that stereotype threat reduces working memory capacity". Journal of Personality and Social Psychology, 85(3) (2003), 440-452. https://doi. org/10.1037/0022-3514.85.3.440

[7] "A Global Approach to the Gender Gap in Mathematical, Computing, and Natural Sciences: How to Measure It, How to Reduce It?" Ed. Roy, Marie-Françoise; Guillopé, Colette et al, International Mathematical Union, June 6, 2020.; https://zenodo.org/record/3882609

[8] https://gender-gap-in-science.org

[9] Michael H.K. Bendels, Ruth Müller, Doerthe Brueggmann, David A. Groneberg: "Gender disparities in high-quality research re- 
vealed by Nature Index journals", January 2, 2018; https://journals. plos.org/plosone/article?id=10.1371/journal.pone. 0189136

[10]Christian Steinfeldt, Helena Mihaljević, Lucía Santamaría and Trang Cao, Gender Publication Gap. https://gender-publicationgap.f4.htw-berlin.de/journals/single. Downloaded on 8.10.2020

[11] Matthew R.E. Symonds, Neil J. Gemmell, Tamsin L. Braisher, Kylie L. Gorringe, Mark A. Elgar: "Gender Differences in Publication Output: Towards an Unbiased Metric of Research Performance", December 27, 2006, https://doi.org/10.1371/journal.pone.0000127

[12] Jory Lerback, Brooks Hanson B: "Journals invite too few women to referee", Nature 541 (2017); https://www.nature.com/news/journals-invite-too-few-women-to-referee-1.21337

[13] https://www.nature.com/news/gender-progress-1.14334

[14]https://www.nature.com/news/gender-imbalance-in-science-journals-is-still-pervasive- 1.21348

[15] https://www.nature.com/articles/d41586-018-05465-7

[16]Chad M. Topaz, Shilad Sen: "Gender Representation on Journal Editorial Boards in the Mathematical Sciences", August 18 , 2016, https://journals.plos.org/plosone/article?id=10.1371/journal. pone. 0161357.

[17] United States Department of Education, Institute of Education Sciences, National Center for Education Statistics. The Integrated Postsecondary Education Data System Salaries, Tenure, and Fringe Benefits Survey; accessed online, April 2016. Available from: https://ncsesdata.nsf.gov/webcaspar.

[18] American Mathematical Society. Annual Survey of the Mathematical Sciences, Department Profile Reports; accessed online, Apr. 2016. Available from: http://www.ams.org/profession/data/annualsurvey/survey-reports\}

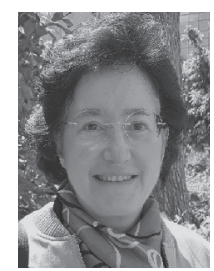

Alessandra Celletti is Full Professor of Mathematical Physics at the University of Rome Tor Vergata and vice-President of ANVUR "Italian National Agency for the evaluation of Universities and Research Institutes". She chairs the EMS Women in Mathematics Committee. She was invited speaker at 6ECM in Cracow in 2012 and gave the public talk at 7ECM in Berlin in 2016. Since 2016 she is Editorin-chief of "Celestial Mechanics and Dynamical Astronomy".

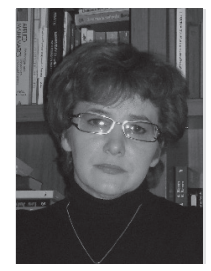

Stanislawa Kanas is Professor of Institute of Mathematics at the Rzeszow University. She is the President and founder of Polish Women in Mathematics and member of EMS Women in Mathematics Committee. She works actively for women, e.g. by initiating and organizing the international conference "On the trail of women in mathematics", delivering the lectures on famous women in mathematics, and supporting younger women studying and working in the field of mathematics. 